\title{
IDENTIDADE E ALTERIDADE DO SER: OS DESAFIOS DA PLURIVERSALIDADE À INTERCULTURALIDADE
}

\section{${ }^{1}$ Raquel Fabiana Lopes Sparemberger ${ }^{2}$ Mauricio Martins Reis}

\begin{abstract}
RESUMO
O presente trabalho tem por objetivo abordar algumas reflexões sobre a relação entre hermenêutica, identidade e alteridade nas sociedades contemporâneas. Enfatiza a questão da identidade numa perspectiva hermenêutica, ou interpretativa, de orientação a partir da qual o ser humano é capaz de tomar uma posição. Reflete sobre a questão identitária e a constituição do Ser. Centrado na questão da identidade,a perspectiva multicultural e intercultural também comparece, pois o trabalho tem como objeto principal demonstrar a constituição de identidades do sujeito a partir do pluriversal e da diversidade de saberes.Utiliza-se do método dedutivo e do procedimento bibliográfico.
\end{abstract}

Palavras-chave: Hermenêutica, Identidade, Interculturalidade, Pluriversalidade

\section{IDENTIDAD Y ALTERIDAD SER : LOS DESAFÍOS DE LA PLURIVERSALIDAD A INTERCULTURALIDAD}

\section{RESUMEN}

El presente trabajo tiene por objetivo hacer reflexiones sobre la relación entre hermenéutica, identidad e alteridad en las sociedades contemporáneas. Resalta la identidad en una perspectiva hermenéutica o interpretativa de orientación, percibiendo el humano como un ser capaz de decidir sobre su posición. Centrado en la identidad, en la perspectiva multicultural e intercultural, el objetivo central es la demonstración de la constitución de identidades del sujeto de modo pluriversal, de la diversidad de saberes, y distintas formas de producción del conocimiento por afuera del centro gravitacional de la racionalidad moderna occidental, eurocentrado. Utilizase del método deductivo y del procedimiento bibliográfico.

Palabras-claves: Hermenéutica, Identidad, Interculturalidad, Pluriversalidad

\footnotetext{
1 Doutora em Direito pela Universidade Federal do Paraná - UFPR, Paraná (Brasil). Professora da Universidade Federal do Rio Grande - FURG, Rio Grande do Sul. (Brasil).E-mail: fabiana7778@ hotmail.com

2 Doutor em Filosofia pela Pontifícia Universidade Católica do Rio Grande do Sul - PUC/RS. Rio Grande do Sul. (Brasil). Professor da Fundação Escola Superior do Ministério Público. Rio Grande do Sul. (Brasil). E-mail: mauriciomreis@terra.com.br
} 


\section{CONSIDERAÇÕES INICIAIS: A IDENTIDADE COMO PONTO DE PARTIDA FILOSÓFICO}

Tomar-se-á a identidade numa perspectiva hermenêutica, ou interpretativa, de orientação a partir da qual o ser humano é capaz de tomar uma posição (TAYLOR, 2011, p. 44). Trata-se da hermenêutica da faticidade na qual estamos inseridos, o horizonte fático irrenunciável no interior do qual os processos de interpretação do mundo (e da própria identidade) são igualmente o culminar de uma autocompreensão. A pergunta acerca de quem somos (identidade) induz para uma orientação moral atualmente oscilante entre o universal e o particular. Mais precisamente, para uma dialética entre o si e o outro que não o si mesmo: não estaria nesse pêndulo a aporia antes denunciada, agora estabelecida em termos jurídicos? Poderia haver uma identidade que tomasse apenas o si e não o outro? E, ao tomar o outro pela postulação da experiência da heterogeneidade, poderia haver o constructo do conceito de identidade? Conforme relata Charles Taylor, as pessoas são modeladas por aquilo que julgam universalmente válido e igualmente por contornos compreendidos como aspectos particulares, numa dupla vertente indissociável da condição de quem somos, especialmente no atributo identitário mais básico segundo o qual um interlocutor humano é capaz de responder por si mesmo (TAYLOR, 2011, p. 46).

A noção de que a identidade enquanto conceito pode solapar a insurgência do outro ou da diferença carrega consigo a aporia da razão. Em realidade seriam três as dificuldades insolúveis desse ponto de vista genérico (racional, da ordem do pensamento e da argumentação), estabelecidas para aquele que pretende pela racionalidade desmentir ou desacreditar determinado conceito, tema ou teoria, oriundos da mesma racionalidade crítica: a aporia de uma razão que persiste em desempenhar sua atividade, depois de ter perdido todo direito à existência; a de uma razão que critica a razão, e com isso compromete os seus fundamentos para a crítica; e a de uma razão que quer solapar o conceito, mas para isso não pode abrir mão dele (ROUANET, 2005, p. 331). Em contrapartida a uma postura crítica contraditória, avessa e arisca às determinações da razão, poder-se-ia incidir na hipérbole racional antípoda: a identidade centrada no "eu" ou na fórmula do Cogito de matriz cartesiana (duvido, sou) consiste no exemplo paradigmático a ambicionar, exaltando, a fundamentação derradeira alçada à categoria de verdade última (RICOEUR, 2014, p. XVI). Os dois opostos se revelam censuráveis e é exatamente no ponto intermediário que se pode erguer a noção de identidade (si ou self) em torno da característica essencial do humano segundo a qual não se pode dispensar alguma orientação para o bem, ou seja, de que essencialmente somos a posição que assumimos em relação ao norte de valores (TAYLOR, 2011, p. 51).

Por isso a questão sobre o sentido do ser - de sua identidade e das respectivas 
configurações morais e jurídicas afeta respectivamente os ambientes teleológico e deontológico - deita lastro no mundo, lugar existencial onde se dá, enquanto horizonte de evento, a abertura para todo o tipo de significação (STEIN, 2010, p. 98). O mundo, lugar da hermenêutica da faticidade, mostra-se um horizonte digno de aposta, naquela recomendação dada por Pascal: se ganharmos, venceremos tudo; se perdermos, não sacrificaremos coisa alguma, porque não ficaremos mais pobres do que já estamos (conforme ROUANET, 2005, p. 347). Em certa medida, essa aposta é preferível às alternativas elencadas como "a vertigem de um racionalismo aporético, a superficialidade de um positivismo míope, ou a aventura de um irracionalismo suicida" (ROUANET, idem, ibidem). Isso significa a solidariedade originária entre pessoa e verdade (PAREYSON, 2005, p. 5), a condição para se justaporem modos coexistentes de se empreender hermeneuticamente o conceito (o histórico e o especulativo), com o fim de se elaborar um conceito interpretativo (hermenêutico) de identidade capaz de se mover no mundo sem atirar-se ao beco sem saída da desconstrução, tampouco se confinando no receptáculo de expedientes teóricos intransigentes. As contemporâneas experiências de alheamento obturadoras da possibilidade de se elaborar racionalmente um conceito levam a um niilismo prático justificado por um déficit fundamental de sentido e por um ceticismo valorativo, a proporcionar a destruição física e espiritual da humanidade (DÜSING, 2006, pp. 14-16).

A abordagem da identidade, pois, convoca preliminarmente um ponto de partida filosófico, cuja base situaremos na hermenêutica do si em Paul Ricoeur. A escolha não se mostra arbitrária, muito menos aleatória, na medida em que a fundamentação hermenêutica em questão se situa "a igual distância da apologia do Cogito e de sua destituição" (RICOEUR, 2014, pp. XV-XVI), isto quer dizer, em torno de uma militância crítica desindexada de qualquer matriz prévia, ou seja, inegavelmente equilibrada e sem pendores inerentes desacompanhados de alguma translúcida razão. Pode-se dizer que o fundamento hermenêutico para o conceito de identidade antepara a unidade antropológica - filosófica - a evitar a desintegração empírica do termo no seio da antropologia cultural (STEIN, 2010, 101). Aliás, referida unidade - a de sentido - se consolida no enfrentamento de conceitos paralelos ao de identidade, com os quais o si (self) se articula, como é o caso do conceito de ideologia, igualmente suscetível de enredamento no problema do círculo vicioso constitutivo da racionalidade humana (a aporia acima identificada em suas três variantes). Consoante Paul Ricoeurpor bem adverte, "se tudo o que dizemos é enviesado, se tudo o que dissermos representa interesses que não conhecemos, como elaborar uma teoria da ideologia que não seja, ela própria, originária” (RICOEUR, 2015, p. 23).

Assim, o próprio niilismo estipulado como a impossibilidade da razão se mostra um 
análogo da versão marxista de ideologia, bem como um semelhante modal à aversão do discurso em sede de direitos humanos, todos eles conducentes ao paradoxo de se insurgirem contra a racionalidade, tomando ela própria como pressuposto para a elaboração dos seus programas teóricos de reprimenda. Ao revés disso, apela-se à estrutura da diferença ontológica como novo modo de fundamentação, uma instância sedimentada no acontecimento hermenêutico mediado pela expressão da linguagem com apoio na experiência do ser humano no mundo (STEIN, 2010, p. 103). Apóia-se a verdade no índice hermenêutico mais profundo atinente à constituição simbólica da estrutura da vida social dos seres humanos (RICOEUR, 2015, p. 25).

A extensão alargada - para não dizer global - de conceitos tipicamente negativos que suspeitam da razãooferece o paradoxo da contradição invencível da qual padecem: o conceito se submete contra si mesmo na sua incontida reflexividade, tornando-se parte do seu próprio campo referente (RICOEUR, 2015, p. 24). Assim Paul Ricoeur qualifica a filosofia de Nietzsche: ao se proclamar crítica a não mais poder frente à certeza elementar de Descartes quanto ao estatuto do "eu existo", agudizando já para a experiência interna do pensamento a ressalva de que se pode tratar de uma ilusão, ela deixa de ser o inverso do Cogito cartesiano para implodir, destruindo, a própria questão da existência humana, sem a qual sequer o pensador poderia colocar em andamento as suas investigações céticas (RICOEUR, 2014, pp. XXVII-XXX). Duvidar melhor, no expoente das conjecturas nietzschianas, significa impossibilitar a própria dúvida como exercício da reflexão filosófica, já que ela anula a própria fronteira entre realidade e ilusão, entre filosofia e mitologia.

A identidade não pode ser aprisionada conceitualmente como se fosse um objeto, muito menos se pode preferir o ato contrário, por igual condenável, consistente em abdicar de sua consideração especulativa. O indício teórico calibrado por Charles Taylor vem à baila mais uma vez, ao afirmar que o self se configura "na medida em que nos movemos num certo espaço de indagações, em que buscamos e encontramos uma orientação para o bem" (TAYLOR, 2011, p. 51). Para ele, noutro passo, a articulação conceitual mínima ou indicativa acerca da identidade não pode ser inflacionada a ponto de se mostrar exauriente ou plena, isto é, de um ponto de vista sinalagmático alheio às dinâmicas hermenêuticas pragmaticamente vivas no interior da comunidade linguística, como se fosse um sistema de mera referência expressivo-declarativa.

Pelo fato de a instituição do si (self) depender também das próprias autointerpretações efetivadas no mundo da vida pelas identidades vivas que acontecem na compreensão prévia da analítica existencial (ou da hermenêutica da faticidade), se qualifica tal pretensão conceitual completa como uma hipótese impossível destituída de efetividade. Eis 
mais um desdobramento da aporia da razão suficiente, por um lado, e da razão desconfiada, por outro, ambas equivocadas por sua desmesurada ambição de totalidade no sentido de respectivamente incluir e excluir objetos em seu arsenal teórico de base: a situação original do self encontra-se num espaço comum no meio de outros, naquilo que Taylor denomina de "redes de interlocução" (TAYLOR, 2011, p. 55).

De se registrar o estatuto fundamental da hermenêutica para Paul Ricoeur, cuja origem mostra-se inclusive anterior (no sentido transcendental de condição de possibilidade) a outras implicações não menos significativas para a filosofia. O conceito de identidade, por exemplo, resta implicado nessa prévia demarcação interpretativa transcendental, e Ricoeur dissocia nele duas projeções antitéticas à noção unidirecional de se conceber tal conceito no sentido de uma configuração absoluta redutível ao destino do portador (si ou self) como um "si mesmo" ou "mesmo" idêntico. Por isso, realiza-se uma abertura dissociativa desse conceito na identidade "idem" (mesmidade) e na identidade "ipse" (ipseidade): esta última carrega consigo uma original e legítima orientação rumo ao outro que não o si mesmo (alteridade) num vínculo de proximidade deveras íntimo a ponto de ipseidade e alteridade constituírem certa dialética implicativa não vislumbrável no mero jogo de oposição comparativa entre mesmo (mesmidade) e outro (RICOEUR, 2014, pp. XIII-XIV). Não por acaso, dizer "si" - na hermenêutica do si - não significa apontar para "mim", de modo que a reflexividade cogitada procura evitar a reduplicação do sujeito em primeira pessoa, um embuste teórico onde o outro não deixa de ser um outro eu (RICOEUR, 2014, p. 198).

Diante da exigência de se balizar o escopo jurídico dessa introdução, mostra-se necessário adentrar na hermenêutica ricoeuriana do si mesmo, cujo lugar epistêmico almeja se encontrar além da oposição extrema entre o Cogito (Descartes) e o anti-Cogito (Nietzsche), focando-a para as determinações normativas relacionadas às categorias do bom e do obrigatório (RICOEUR, 2014, XXXIII). O filósofo concebe nessa dimensão normativa (moral, ética e jurídica) o desenvolvimento filosófico pleno e apropriado para a dialética entre o si e o outro. A dialética em comento apura um relacionamento que pressupõe para o self algo para além de uma neutralidade idêntica confinada à autoconsciência instantânea da dentidade, apontando para um espaço (com profundidade temporal narrativa) repleto de indagações morais, característico da estrutura transcendental inescapável do ser no mundo, encarregado de orientá-lo em sentido (TAYLOR, 2011, pp. 70-74). Ademais, o si em Ricoeur ostenta essa condição hermenêutica na medida em que não se confunde com a análise imediata do si como eu (tal qual as filosofias desdobráveis do Cogito e de seu irrefletido contrário preconizam), além do aspecto de nele estar implicada a tarefa da reflexão em processos cuja análise precede o retorno para esta categoria, a qual, portanto, não se funda 
intransitivamente como causa soberana (RICOEUR, idem, ibidem).

Importante dizer que o elemento transcendental iluminado pela hermenêutica do si através da dialética reflexiva da alteridade não pode ser confundido com outras propostas teóricas que manejam com outro tipo de proposta para a estrutura filosófica da transcendentalidade, especialmente se esta deita raízes na mesmidade do sujeito cognoscente. Ao rejeitar o reducionismo da identidade na figura do "eu" ou do "ego" solipsista, como a fenomenologia de Husserl concebe o ego transcendental numa espécie de gênese a partir do mesmo (RICOEUR, 2014, p. 201), isto é, segundo a qual o conhecimento interpessoal acerca do outro - apenas se perfaz na base de inferências empíricas a partir do sujeito em primeira pessoa (GIDDENS, 2002, p. 52), Ricoeur promove um entrelaçamento dinâmico reflexivo entre o si e o outro em que a subjetividade tomada na primeira pessoa depende da intersubjetividade pela conexão irremediavelmente pública do ser humano com linguagem: trata-se do fato de que o ser humano confronta ou relaciona a sua própria linguagem com a linguagem dos outros (TAYLOR, 2011, p. 58).

Desta feita, recusa-se drasticamente o solipsismo na sua navegação prioritária a partir da qual a subjetividade funda a intersubjetividade. Na concepção hermenêutica ricoeuriana, então, o transcendental permanente de horizonte de sentido constitui-se analogamente como uma clareira ou abertura para o mundo, condicionando ele próprio à extensão de sua possibilidade (nem desmedida, muito menos enclausurada), de maneira a albergar a ambivalência entre a unidade e o fragmentado, entre a constância de algum critério que impeça o silêncio da razão e a historicidade do questionar sobre a identidade e o agir humanos ao longo da história (RICOEUR, 2014, XXXIV-XXXV). Para o pensador francês, a alteridade fornece ao conceito de si - e aos seus desdobramentos normativos - uma indispensável polissemia, nele imprimindo "o selo da diversidade de sentido que desbarata a ambição de fundamentação última” (RICOEUR, 2014, p. XXXVI). A hermenêutica do si, nada obstante, pretende um tipo de verdade, uma denominada "atestação" veritativa conciliável ao juízo dialético de análise e reflexão efetuado junto ao self e ao outro (por igual, face à ipseidade e à mesmidade), situada num ponto intermediário menos incisivo do que o Cogito cartesiano, embora mais atuante comparado ao arrazoado niilista em Nietzsche (RICOEUR, 2014, pp. XXXVI-XXXVII).

A hermenêutica do si desemboca efetivamente em solo jurídico estrito quando da indagação sobre o lugar filosófico do justo (RICOEUR, 2008, p. 7), ou seja, na intersecção dos eixos horizontal e vertical essencialmente característicos da identidade, o primeiro vinculado à constituição dialógica do self (ipseidade), o segundo subordinado aos predicados que qualificam a conduta humana (moralidade). Trata-se, portanto, de filosoficamente 
transpor-se o inventário sociológico - de notável contribuição teórica - responsável por identificar os parâmetros fundamentais da vida humana nos contextos da atividade social, a saber, aqueles que demandam fortalezas ontológicas e epistemológicas a respeito de quem somos, com quem nos relacionamos, como dotamos a nossa vida de sentido e para que nos destinamos enquanto identidade narrativa projetada no tempo histórico (GIDDENS, 2002, pp. 49-56). E essa transposição rumo ao lugar da justiça requer necessariamente a fiança simbólico-pragmática mediada pelo aparato da instituição, não no sentido burocráticofuncional de serem atuadas competências e foros declaratórios de direitos, mas no apelo substantivo do "si mesmo" como "cada um", no tratamento correlativo a delinear a cada qual o que é seu (RICOEUR, 2008, p. 8).

Com a instituição do procedimento judiciário, encarna-se ali o papel qualitativo do “julgar", estabelecendo-se o magistrado (menos na sua pessoa e mais na sua função institucional) na condição de terceiro entre as partes do processo litigioso, uma espécie de terceiro em segundo grau garantidor da adequada distância em vista a cada um dos litigantes a corroborar o apelo de justiça constante no adágio latino suumcuiquetribuere, a cada um o que é seu (RICOEUR, 2008, p. 9). A investigação em torno do justo, convencionado na estrutura deontológica dos ordenamentos jurídicos positivados, remonta, a propósito, ao fundamento da moralidade, à teleologia ética da constituição moral da ação que aspira a uma vida boa: consoante Ricoeur, “a justiça (...) faz parte integrante do querer viver bem” (RICOEUR, 2008, p. 10). Isso se exemplifica facilmente na constatação intuitiva de anterioridade da conscientização do injusto à do justo, em virtude dos males que o ser humano é capaz de infligir a seus semelhantes no contexto do compartilhamento social, ademais do fato dessa potencial violência a ser contingenciada (senão evitada) não se bastar como argumento definitivo na passagem do bom ao obrigatório (RICOEUR, 2008, p. 12).

A distinção eventualmente preconizada na literatura entre ética e moral não possui outra finalidade para a hermenêutica ricoeuriana senão a de convencionar uma divisória meramente esquemática, sem dissolver o plano comum a conectá-las numa genealogia dos costumes atrelada à mediação de continuidade no caminho do retorno para o si mesmo. Noutros termos, Ricoeur prescreve uma linha continuativa entre ser (identidade) e dever-ser (moralidade) que rechaça uma suposta dicotomia em abismo dessas duas constelações, especificando, ademais, no lugar filosófico do justo, a implicação dialética daquilo que é considerado bom, a ética, com o programa jurídico imposto como obrigatório, a moral (RICOEUR, 2014, p. 184). Passo adiante, a figura do magistrado como terceiro institucional em segundo grau apenas efetivará a norma de justiça se houver imparcialidade e independência de julgamento, cujo cerne se alcança mediante a referência indispensável ao 
código jurídico deontológico, melhor dizendo, à sua ideia originária de obrigação assentada filosoficamente na reivindicação de validade universal vinculada à própria noção de lei (RICOEUR, 2008, p. 13).

O singular relacionamento da ética, tomada como o desiderato de uma vida boa, com a moral, voltada para a articulação jurídica desse desiderato mediante o estabelecimento de normas com alcance universal e poder coercitivo, significa para Ricoeur uma espécie de círculo virtuoso de recíproco suporte justificativo entre as duas esferas. Isso faz conceber um caminho hermenêutico não mais intransponível (como se supõe para autores que defendem o abismo ou fosso irredutível entre ser e dever-ser), capaz de efetivar o encontro dos domínios teleológico (ética) e deontológico (moral), especialmente quando se põe em relevo o mútuo processo de legitimação, principiado pela primazia da ética sobre a moral. Assim colocada tal proeminência, Ricoeur elabora dois passos subsequentes, a necessidade de a finalidade ética passar pelo crivo da norma jurídica positivada e a legitimidade de a norma recorrer ao desiderato ético quando houver impasses práticos, elaborando para cada qual terminologias específicas, quais sejam, a correspondência entre ética e estima de si mesmo e entre moral e respeito por si mesmo: em linha sucinta de definição, "o respeito a si mesmo é o aspecto assumido pela estima a si mesmo sob o regime da norma” (RICOEUR, 2014, p. 185).

Daí se engendra a hermenêutica do si voltada para a resolução de impasses drásticos na esfera do direito positivo, ocasião concreta em que nenhuma norma conseguirá carrear suficientemente, com caráter satisfatório de interface entre a ética e a moral, o guia seguro para o exercício efetivo do respeito simbolizado pela norma no ordenamento jurídico. A hermenêutica da identidade se aproxima aqui da hermenêutica prática (cujo apogeu se instala na hermenêutica filosófica de Hans-Georg Gadamer) de deliberação reflexiva em vista de ponderar o melhor caminho para a vida (RICOEUR, 2014, p. 194), de enfrentar o "trágico da ação" (RICOEUR, 2008, p. 17). A consistência do justo, nesse aspecto, exorbita a fórmula estrita do positivismo exegético mais rasteiro, pois ela não se exaure no ponto de vista deontológico de modo a se desvencilhar do programa ético rumo à "visada do bem" no instante de aplicação típico do universo da sabedoria prática ínsita à hermenêutica da realização interpretativa do direito.

A reivindicação de universalidade da justiça, pois, "fazem-na dividir-se entre a referência indelével ao bem e a atração que sobre ela exerce o estatuto puramente procedimental das operações constitutivas da prática legal” (RICOEUR, 2008, p. 14), ou seja, “o nível deontológico, considerado com razão como o nível privilegiado de referência da idéia de justo, não poderia tornar-se autônomo a ponto de constituir o nível exclusivo de referência" (RICOEUR, 2008, p. 15). Assim o justo se volta tanto para o lado ético do bem, evocando a 
projeção das relações interpessoais nas instituições, quanto para o lado moral da conformidade ao direito positivo, onde o sistema jurídico se retroalimenta com sua disciplina regulatória a partir da orientação de expectativas endossada pelas normas vigentes (RICOEUR, 2014, p. 219). Mais importante, há um elo entre obrigação e formalismo em Ricoeur que fomenta um movimento de volta da moral à ética (do direito positivo ao senso daquilo que seja considerado bom), porém, numa retomada reflexiva de enriquecimento entre os dois âmbitos calibrada especialmente pelo investimento hermenêutico tópico correlato ao problema concreto em situação de impasse pendente de ser resolvido pelo juízo prático (RICOEUR, 2014, p. 227).

A hermenêutica do justo, poderíamos denominar assim, se estrutura em última análise na decisão singular levada a cabo por ocasião de um impasse de conflito e incerteza (RICOEUR, 2008, p. 17). É na especificidade decisória da hermenêutica do justo que se identifica, contudo, as raízes originárias conducentes à hermenêutica do si, porquanto a esfera prática de deliberação institucional para efeito de se resolverem conflitos não deixa de ser um desdobramento do espectro reflexivo interior ao agir humano e à sua identidade. Assim se pronuncia Paul Ricoeur a respeito dessa relação: "é num trabalho incessante de interpretação da ação e de si mesmo que prossegue a procura de adequação entre o que nos parece o melhor para o conjunto de nossa vida e as escolhas preferenciais que governam nossas práticas" (RICOEUR, 2014, p. 196).

Retoma-se a metáfora do círculo (virtuoso) hermenêutico em vista do "jogo de vaivém entre a ideia de "vida boa" e as decisões mais marcantes de nossa existência", que ocorre "como um texto no qual o todo e a parte são compreendidos um por meio do outro" (RICOEUR, idem, ibidem). Além disso, o filósofo não se furta de expressar, para o exercício de tal juízo prático diante do conflito de interpretações, a demanda por uma resolução adequada compatível com o contexto de uma sabedoria prudencial distinta do espaço de verificação mais estrito típico das ciências empíricas observacionais: eis aqui mais uma vez o critério de plausibilidade da "atestação", o qual se compraz com uma evidência atenuada onde a certeza se transforma em convicção acerca do bem julgar e do bem agir (RICOEUR, 2014, p. 197). Essa atestação ricoeuriana se denomina "fronética" (phronesis), consistente em "explorar a zona média na qual se forma o juízo, a meio caminho entre a prova, submetida à injunção lógica, e o sofisma, motivado pelo gosto de seduzir ou pela tentação de intimidar" (RICOEUR, 2008, p. 18).

A grande questão na hermenêutica do justo ecoa em saber se a redução do jurídico (moral) ao procedimento institucionalizado, a saber, ao reduto deontológico autonomizado nas leis, não deixaria escapar "um resíduo que exige certo retorno a um ponto de vista 
teleológico, não à custa da renegação dos procedimentos formalizantes, e sim em nome de uma demanda à qual esses mesmos procedimentos dão voz" (RICOEUR, 2014, p. 259). Eleva-se agora, nessa inevitável ocorrência factual consistente no transbordamento das balizas do procedimento, em virtude da repercussão negativa de injustiça particular (o resíduo que se deixa escapar) derivada do impacto mal consentido da concretização da fórmula moral estipulada pelos cânones convencionais da instituição jurídica, a objeção do caráter casuístico contextual frente à exigência de universalidade em complexo grau de efetivação (RICOEUR, 2014, p. 330). Trata-se de um dos problemas privilegiados pela lupa da hermenêutica ricoeuriana do justo - a ética da argumentação e os seus limites no confronto entre universalidade e contextualismo - de que se permitirá socorrer em descritivo objetivo no deslinde desse preâmbulo.

A exigência de universalidade ou universalização repousa seu fundamento no princípio da autonomia da pessoa humana, o qual institui um dos aspectos mais soberanos da identidade como ipseidade, cuja faceta moral conecta-se mais diretamente ao quadro das relações interpessoais norteadas pelo devido respeito às pessoas e das instituições administradas pela diretriz de justiça (RICOEUR, 2014, p. 333). Ocorre que os limites de aplicação de um código deontológico incondicionalmente posto resultam mostrados na ambiência do específico problema decidendo, oportunidade em que a contextualidade da diferença casuística poderá, conforme seja a envergadura da fundamentação decisória em termos de coerência e integridade institucional (especialmente considerado o laço reflexivo que remonta à teleologia ética), integrar - e não quebrantar - o atributo de universalidade inerente ao produto legislativo positivado. Paul Ricoeur bem decifra esse incontornável paradoxo: "quanto mais estritamente procedimental uma concepção de justiça pretender ser, mais recorrerá a uma ética argumentativa para resolver os conflitos por ela mesma engendrados" (RICOEUR, 2014, idem, ibidem).

A inestimável façanha do ser humano em mediar reflexivamente a cada conflito concreto a precedência de universalidade diante dos problemas de contexto na plataforma das decisões acerca do justo, com vistas ao feito de resolver a imensa complexidade do real que o circunda, faz imbricar a identidade na história. É no mundo social que os seres humanos elaboram o processo de universalização, o qual se erige "como exigência de um processo de construção de mundos intersubjetivos igualitários (universalismo igualitário), participativos e capazes de reconhecer as diferenças” (OLIVEIRA, 2012, p. 277). Uma das maneiras de colaborar para o êxito nesse processo de emancipação consiste no reconhecimento da alteridade, sem quedar na pura instrumentalidade do eixo dialético - constitutivo da identidade - entre o si e o outro (OLIVEIRA, 2012, p. 279), tal qual recomendado pela 
hermenêutica de Ricoeur.

Não há uma contraposição inerente estrutural entre as políticas de universalização e de afirmação da diferença. O que existe é um pendular jogo de forças cujo concerto harmônico deve ser contemplado, pela via da ética da argumentação, evitando-se apelos exacerbados seja em prol da tutela do abstrato e idêntico tratamento das pessoas, seja em benefício da proteção irrestrita de suas identidades culturais. Um exemplo de criticável extrapolação discursiva reina na "apologia da diferença pela diferença que, em última instância, torna todas as diferenças indiferentes, uma vez que torna inútil qualquer discussão" (RICOEUR, 2014, p. 334). Pode-se dizer que Ricoeur mais uma vez aposta numa estratégia de conciliação para integrar as objeções do contextualismo em práticas reflexivas que levem ao aperfeiçoamento das políticas institucionais de universalização: resta ao interlocutor da diferença na roda do discurso levar a sério o requisito de universalidade de modo a atender "as condições de contextualização dessa exigência", com o que se substitui o antagonismo entre argumentar e convencionar "por uma dialética fina entre argumentação e convicção" (RICOEUR, 2014, p. 335).

A ética da argumentação possuiria uma ação corretiva mediadora em meio aos demais jogos de linguagem presentes nas práticas comunicacionais cotidianas, porque ela se apresenta como "instância crítica atuante no âmago de convicções que ela não tem a tarefa de eliminar, mas de levar ao nível de „convicções sopesadas ${ }^{\mathrm{eo}}$ (RICOEUR, 2014, p. 336). Talvez o crédito ricoeuriano na convicção como parceiro inalienável neste equilíbrio reflexivo entre a exigência de universalidade e o reconhecimento das limitações contextuais tenha o poder de inibir o paradoxo histórico apontado por Manfredo Araújo de Oliveira: "nossas sociedades se preocupam cada vez mais em definir e proclamar listas de direitos humanos e, ao mesmo tempo, se mostram incapazes de transcender o plano formal de sua proclamação e de efetiválos" (OLIVEIRA, 2012, p. 282). Ilumina-se aqui o ponto nevrálgico de reforço recíproco entre deontologia e teleologia, entre a moral e a ética, a saber, localizado "no equilíbrio reflexivo entre ética da argumentação e convicções sopesadas” (RICOEUR, 2014, p. 337), onde "a ética da argumentação é testada no conflito das convicções (RICOEUR, 2014, p. 339). Não se ignore, por último, que o árbitro para o destino de um consenso somente pode descender de um reconhecimento no plano da plausibilidade, dessa "atestação" hermenêutica rumo a uma verdade possível capaz de nos alcançar novas propostas de sentido características de universais compartilháveis ou assumidos por convicções presentes em modalidades concretas - espontâneas e incoativas - de vida em sociedade (RICOEUR, 2014, p. 338). 


\section{A BUSCA PELA ALTERIDADE PARA ALÉM DA UNIVERSALIZAÇÃO E DA DIFERENÇA}

Gadamer afirma que o compromisso da hermenêutica é com "a conservação e a nãosupressão da alteridade do outro no ato compreensivo" (1994, p. 13). A cultura da alteridade significa antes de tudo a valorização da linguagem e da tradição como instâncias que estabelecem condições interpretativas para a emergência do novo e do diferente. $\mathrm{O}$ ser humano está, constantemente, buscando o sentido da vida. Em tempos em que o cogito cartesiano e os sistemas totalizantes não mais dão conta da pluralidade que é o ser humano,

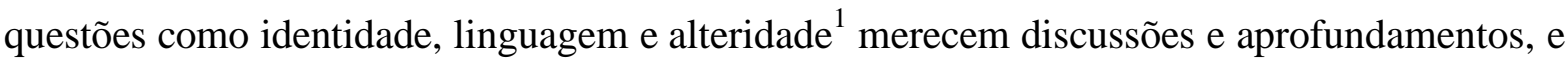
a hermenêutica pode contribuir para o desvelar do ser, da universalidade e da diferença.

A alteridadeconsiste em ser capaz de apreender o outro na plenitude da sua dignidade, dos seus direitos e, sobretudo, da sua diferença. Quanto menos alteridade existe nas relações pessoais e sociais, mais conflitos ocorrem. Percebe-se, nessa linha de raciocínio, que os conceitos de identidade e alteridade apresentam uma estreita ligação, ou seja, existe uma relação de reciprocidade. Assim, do mesmo modo que a noção da alteridade se constitui só a partir de um marcado "eu", a mera presença do outro diferente de mim possibilita o pensar sobre as condições desta minha identidade. Para Nancy Rita Vieira Fontes (s,d, p. 6) o conceito de uma alteridade interior quebra com a visão de grupo homogêneo "nós",como acima explicitado,e levanta o assunto sobre a construção da identidade.

Stuart Hall (1999, p. 68-75), ao examinar o conceito de identidade, destaca dois componentes determinantes: a) a noção da identidade cultural que corresponde à perspectiva de uma história em comum que representa a experiência de um determinado coletivo. A partir desta vivência acumulada, estabelece-se um contexto cultural que funciona como código comum e influi, de alguma maneira, em todo indivíduo pertencente ao coletivo. Esta visão representa uma concepção de relativa continuidade e da representação homogênea de uma entidade unida (a chamada universalidade); b) outro componente refere-se à heterogeneidade dentro de um todo coletivo. Esta segunda percepção apresenta um conceito de construção e transformação permanente mediante uma negociação contínua da identidade de cada sujeito (desvelar do ser). Pode-se denominar esta visão de posicionamento individual, de maneira que a identidade do sujeito se define como balanceamento de uma representação individual dentro de pontos de identificação de um contexto cultural estabelecido.

\footnotetext{
${ }^{1}$ A palavra alteridade vem do latim alter, outro/a é introduzida na filosofia contemporânea pela fenomenologia. Já na filosofia de Feuerbach fala-se da dialética da relação Eu-Tu e da presença do outro. E é principalmente na filosofia de Emmanuel Levinas que o conceito de alteridade vai se desenvolver de maneira universal e afirmativa. A presença da alteridade no pensamento cria uma nova perspectiva para a Ética, educação e para a antropologia. A alteridade apresenta-se como a novidade constante no processo e desenvolvimento da cultura (SIDEKUN,2007, p.47).
} 
A questão da identidade e da alteridade possibilita inúmeros olhares nas mais diversas direções. Em tempos de globalização não há uma única resposta para a questão da identidade; ao contrário, as identidades surgem ou ressurgem com muitas roupagens, impossibilitando, assim, uma visão única sobre essa temática. As velhas identidades, que por muito tempo davam sustento ao mundo social (as universais), estão em declínio, envolvendose hoje a questão da identidade num processo de amplas mudanças. Insere-se na mesma problemática a cultura e sua importância no fortalecimento dos laços sociais, bem como na formação da identidade de um povo, tornando-se, por isso, um elemento essencial para a compreensão das sociedades e para a análise de suas diferenças. Percebe-se, que o debate sobre universalismos e relativismos e condições identitárias tem sido objeto de grandes debates na atualidade.A condição das sociedades atuais é marcada pelo surgimento de novas formas de política identitária em todo o mundo, intensificando as tensões entre as diversas culturas existentes.

As lutas identitárias se fazem mundialmente presentes, sendo que as reivindicações identitárias de gênero, raça, etnia e orientação sexual são um desafio para os Estados- Nação e para a democracia. Com o processode globalização visualiza-se certa integração global juntamente com a desintegração sociocultural e com o surgimento de resistência por parte de interessados em proteger o local, seus modos de vida, sua autonomia e seus valores. Os movimentos para manter a pureza e as particularidades de uma cultura chocam-se, no entanto, com certas questões democráticas e também de desvelamento do “eu”. É nessa perspectiva, segundo Benhabib (2006, p.10) que, como exposto anteriormente, a filosofia não acredita na pureza das culturas, ou na possibilidade de identificá-las como totalidades significativas diferenciadas. Acredita-se, isto sim, que as culturas são práticas humanas complexas de significação, de organização e de atribuição, divididas internamente por relatos em conflito. Assim, é justamente no mundo social e na construção de mundos intersubjetivos igualitários (universalismo igualitário), participativos e capazes de reconhecer as diferenças que ocorrem e surgem diálogos complexos entre as culturas.A luta pelo reconhecimento do diálogo intercultural pode levar à separação, como também à compreensão e ao aprendizado mútuo. Num Estado Democrático de Direito preservar a cultura de uma minoria significa enaltecer a democracia. Neste sentido, Charles Taylor assevera que a política de reconhecimento é fundamental, uma vez que o diálogo intercultural é fator preponderante para a formação da identidade cultural do indivíduo, mesmo porque o indivíduo está em constante relação com outros sujeitos, ou seja, para Taylor a pessoa não é um ser isolado, mas sim um ser dentro de uma cultura. Para este autor a política de reconhecimento comporta reconhecer a pessoa em sua cultura, a identidade cultural da pessoa e, como derivado, a prática pelo Estado de uma 
política da diferença que abandone as estratégias de assimilação das culturas à cultura dominante (percebida como única e universalizante), e disponibilize recursos para que as culturas se mantenham e prosperem sem perder sua identidade(TAYLOR, 1998, p.85). Isto significa que as identidades não podem ser aprisionadas como se fossem um objeto dentro de uma cultura universalizante, é preciso constantemente o auto-reconhecimento da ipse, pensar o outro que não só a si mesmo, isto é alteridade.

\section{IDENTIDADE,ALTERIDADE E AMPLIAÇÃO DO MULTICULTURALISMO: CATEGORIAS EM (RE)CONSTRUÇÃO}

Nessa trajetória filosófica pelos caminhos de uma ontologia hermenêutica, é possível considerar que o conceito de identidade pode ser compreendido em "Si mesmo como outro". Na elaboração do conceito de identidade para Paul Ricoeur, chamada de narrativa, percebe-se a presença das chamadas identidades - pessoal e coletiva (SALES, 2009, p.3). Segundo Sales (2009, p. 2), "nesse movimento de aproximação, distinção e entrecruzamento o sujeito só pode ser compreendido como sendo atravessado e constituído por uma série de mediações e desdobrado no tempo".

Pelo visto, a identidade não pode ser compreendida como algo estático, por estar sempre em construção e reconstrução. Para Santos (2008, p.145), "a identidade é uma categoria política, pois se torna a defesa de um grupo ou coletividade, uma defesa de si frente a uma possível ameaça do outro". Paradoxalmente, a globalização produz a homogeneização de muitos valores, práticas e gostos, mas também é propulsora de diferentes expressões culturais. O cenário atual é amplamente marcado pelos valores advindos das relações capitalistas, deixando na periferia a solidariedade e as forças sociais alternativas. Nesse viés, a dominação cultural é bastante clara como forma de solidificação das bases capitalistas, das políticas de economia de mercado, do pensamento dominado pela razão científica, da propagação do individualismo.

Em oposição a esse cenário hegemônico, o meio de vida local torna-se uma grande saída para reafirmar a identidade, que está intimamente ligada à língua e à cultura de um povo. A localização proporciona uma relação de originalidade, de pertencimento e de autoreconhecimento, e isso é muito visível nas comunidades de emigrantes, os quais conseguem manter relações estreitas com sua cultura, alimentando assim o vínculo espiritual. Como lembra Bauman (2005), a retomada da questão da identidade se dá a partir do momento em que a condição de pertencer fica ameaçada - caso do atual processo de globalização homogeneizante e uniformizador -, ou seja, a ideia de identidade nasce a partir de uma crise 
de pertencimento e de auto-reconhecimento de si e do outro. Para este autor, "A ideia de "identidade" nasceu da crise de pertencimento e do esforço que esta desencadeou no sentido de transpor a brecha entre o "deve" e o "é" e erguer a realidade ao nível dos padrões estabelecidos pela ideia - recriar a realidade à semelhança da idéia" (BAUMAN, 2005, p. 25).

Pelo fato de todo ser humano ter fortes laços com o local em que se insere, existe um sentimento de pertencimento e de auto-reconhecimento de si, razão pela qual o lugar se torna importante para a cultura, para a natureza, para a economia e principalmente para a identidade. Segundo Escobar (2005), o lugar - como a cultura local - pode ser considerado „o

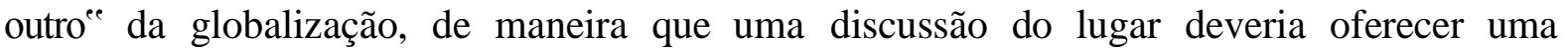
perspectiva importante para repensar a globalização e a questão das alternativas ao capitalismo e à modernidade.

Essa defesa do lugar permite enfatizar quatro direitos que são fundamentais: a identidade, o território, a autonomia política e o desenvolvimento. Para Oliveira (2006, p. 34), "possuir uma identidade é uma realidade que se impõe no mundo da vida como algo primordial", pois quando há o reconhecimento da cultura local e de quem efetivamente somos ou construímos a partir de um norte de valores, o diálogo poderá acontecer, direitos poderão ser igualados e a participação de grupos excluídos nas decisões políticas e governamentais podem tornar-se realidade. Segundo Cesnik e Beltrame (2005, pp.25-47), a globalização reforçou as possibilidades de compartilharmos diversas identidades ao mesmo tempo, pois nos movemos com maior facilidade de uma cultura a outra, aprendemos línguas com rapidez, somos filiados aos valores da democracia, que nos fez mais tolerantes e podemos sentir com instantaneidade as angústias de um povo distante de nós. Essas possibilidades não mutilam a relação original com sua cultura, que até se reforçam pela percepção da diversidade.

Nessa possibilidade de alargamento do multiculturalismo, os efeitos do processo de globalização proporcionaram “o enfrentamento entre diferentes culturas que podem estar produzindo uma comunidade de diálogo e também de interdependência" (BENHABIB, 2006, p. 76).Para essa autora a globalização está criando um enfrentamento entre as culturas, línguas e nações, que acabaincidindo sobre a vida das pessoas, para tanto, o diálogo intercultural é uma importante ferramenta de pacificação. Percebe-se, assim, que a linguagem do eu e do outro se entrelaçam para constituir novas identidades a partir do diálogo das diferenças.

Importa, no entanto, não olvidarde que o processo de globalização cultural não é de todo nocivo, desde que não imponha sua uniformização ou o fim da diversidade. Interessa, por isso, a crescente necessidade do exercício da tolerância, que significa a não-interferência nos comportamentos culturais distintos, preservando o respeito e o reconhecimento nos planos ético e jurídico, em especial no que se refere às minorias étnicas. 


\section{CONSIDERAÇÕES FINAIS: IDENTIDADEE ALTERIDADEE O PAPEL DAS CONSTITUIÇÕES EM BUSCA DE UMA PLURIETNICIDADE E PLURICULTURALIDADE}

A relação entre cultura, identidade e alteridade inseriu-se, nos últimos anos, no debate em torno do conteúdo e do papel das Constituições, tanto no que tange aos direitos das minorias, às reivindicações territoriais, à proteção dos direitos culturais, à língua, aos currículos escolares, quanto aos preceitos que fundamentam as Constituições. É necessário que se reconheça a plurietnicidade e apluriculturalidade que estão presentes na formação da maioria dos Estados, o que vem justificar a afirmação de que os Estados não possuem uma composição homogênea e, com isso, o reconhecimento, sob a forma de tutela, de todos os grupos presentes em sua formação é imprescindível para que a dignidade humana seja realmente protegida e respeitada. Sabe-se que a universalidade ou a universalização tem seu fundamento no princípio da autonomia e da dignidade da pessoa. Esta autonomia diante da universalidade possibilita o reconhecimento do eu e do outro nas diferenças plurais e no sentimento de pertencer a algum lugar. $\mathrm{O}$ que se busca, segundo Santamaria, citando Dussel (2015, p.138), é que se alcance a partir da ética da alteridade, uma abertura do sujeito, para que este seja capaz de compreender o novo e a história que se construiu a partir do seu exterior.

A respeito da identidadenacionalou cultural, Paviani (2004, p. 76-77), asseveraque a identidade de um povoou de umaculturaaponta para um conjunto de costumes, comportamentos, valores, obras e para elementossocioculturais, como a religião e a língua. Alerta o autor, porém, que o conceito de identidadenacionalpode se tornar um instrumentoequivocado da realidade cultural de um povo, umavezquetodaidentidade é constituídasobre a diferença. Dessa forma, na procura da identidadenão se podemesquecer as diferenças, o que se envida a promover uma abertura inclusive na dimensão do conhecimento. Assim, para Lacerda (2014, p. 17), "abre-se a perspectiva de se construirmundosabertos e plurais, mais dialógicos e compreensivos, sem a pretensão de queexistaalguémquehabite o lugar supremo capaz de determinar o que é verdadeiro e universal”. Isto é pluriversalidade e nãouniversalidadeepistêmica. No âmbito do constitucionalismopodeseverificarelementosdesteprocessopluriversal ${ }^{2}$ no chamado "novo constitucionalismolatinoamericano".

\footnotetext{
2 Ao nos valermos da ideia de pluri-versalidade queremos evidenciar as diversas formas de explicar o mundo, um projeto pluriversal diz respeito a um "mundo onde caibam muitos mundos". O oposto de universal, nesse sentido, já não é o particular, mas o múltiplo, o diverso, o heterogêneo (MIGNOLO, 2007, p. 163).
} 
Sobretudo verifica-se um questionamento dos marcos teóricos e epistêmicos do constitucionalismo moderno/colonial e uma ressignificação deste a partir de sujeitos e saberes tradicionalmente subalternizados.Pluriversal porque possibilita a multiplicidade de identidades nacionais num dado território, assim como a ideia de um Estado plurinacional (Bolivia, Equador) tem como pressuposto a diversidade de saberes, de formas de percepção de mundo e distintas formas de produção do conhecimento fora do grande centro gravitacional da racionalidade moderna, representado pelo mundo ocidental, eurocentrado (LACERDA, 2014, p. 18).

Nessa perspectiva, do reconhecimento da pluriversalidadeepistêmica, as identidades se reafirmam para além da chamada colonialidade do ser, que segundo Mignolo se configura a partir da chamada colonialidade do saber. A colonialidade do seré, portanto, uma das resultantes do processo de conquista que, pautado pela ética de guerra se perpetuou na modernidade/colonialidade, agindo sobre todos os sujeitos que não se enquadraram/enquadram no modelo eurocêntrico de "ser humano" (masculino, heterossexual, branco, burguês, cristão), pois sendo o colonizador a medida de todos os outros seres humanos, restaram os colonizados/as condenados/as à não-humanidade. Percebe-se, assim, que tal colonialidade caracterizou e definiu as identidades, porque a colonização da linguagem de um povo é, consequentemente, a colonização de seu "ser", a colonização de sua identidade, de sua subjetividade. O que se busca é a emergência de subjetividades coletivas e "sujeitos coletivos".

Este contra-movimento emergente que visaa questionar as identidades submetidas à colonialidade do poder, do saber e principalmente do ser, aflora a constituição da condição básica da possibilidade de êxito das experiências de construção dos Estados "plurinacionais": "a interculturalidade ou diálogo intercultural" (LACERDA, 2014, p.18).Para isso é necessário, segundo Wolkmer (2015,p. 96), “(r)eescrever um novo modo de vida, estimular a inserção cultural para outras modalidades de convivência interculturais, de relações sociais e regulamentações das práticas emergentes e constituintes por lutas sociais".Segundo Lacerda (2014, p.17), sabe-se, que não é, e não será, na concepção liberal de interculturalidade, tradicionalmente associada à ideia de "multiculturalismo", como expressão da coexistência "harmoniosa" da diversidade sob a batuta de valores pretensamente universais herdados do legado ético e filosófico eurocêntrico, e ambientado nas condições de exploração e dominação proporcionadas pelo modeloeconômico neoliberal, que tais alterações ou modificações ocorrerão. Não é nainterculturalidade que advoga poder "resolver" o problema histórico da exclusão das minorias étnicas e povos indígenas através de sua inclusão em um modelo de Estado que permanece "monocultural", "eurocentrado" e reprodutor de relações coloniais de 
poder (LACERDA, 2014, p.17-18).

Espera-se que,nas novas identidades, o diálogo ocorra a partir do conceito de “interculturalidade crítica” (WALSH, 2007, p. 47). Para a autora, trata-se de uma interação entre pessoas, conhecimentos, práticas, lógicas, racionalidades e princípios de vida diferentes. Uma interação que admite e que parte das assimetrias sociais, econômicas, políticas e de poder e também das condições institucionais que limitam a possibilidade de que o "outro" possa ser considerado sujeito com capacidade de atuar (WALSH, 2009, p. 45).

A perspectiva "crítica" de interculturalidade não se traduz simplesmente na convivência passiva com as diferenças, tolerando-as, mas na busca pela construção do novo a partir das próprias diferenças e buscando a ruptura da lógica da colonialidade.Essa ruptura, em seu fundamento, recuperou o princípio da interculturalidade, da alteridade e do reconhecimento destes povos,garantiu-lhes autonomia e jurisdição dentro de seus territórios, direitos de participação dentro e fora destes. Os povos aparecem como sujeitos de amplos direitos coletivos, alguns de caráter interno, outros por meio de aparatos públicos e outros pelo diálogo intercultural com a sociedade.É por isso que Ricoeur (1955, p. 35), de um lado, procura desabilitar as chamadas teorias da deposição do outro; e, de outro, busca encontrar uma alternativa para um novo tratamento do problema do sujeito e das sua construção identitária. Cabe destacar, nesse sentido, que o autor orienta sua exposição para mostrar que o reconhecimento do outro não se deve dar dentro dos parâmetros duma relação pessoacoisa; mas, diversamente, segundo uma relação entre pessoas. O outro a ser reconhecido deverá ser sempre tomado como um "fim em si”" e não como um mero "meio". Em outras palavras, o outro não poderá ser apreendido em momento algum como "coisa", dado que é, inicialmente, uma pessoa com dignidade moral. Isso implica na ética do dever e do respeito, sua existência é sua dignidade, seu valor não é comercial e ela não tem preço” (RICOEUR, 1955, p. 29). As relações interculturais podem possibilitar isso na atualidade.

\section{REFERÊNCIAS}

BAUMAN, Z. Identidade: entrevista a Benedetto Vechhi/ZigmuntBaumann. Tradução de Carlos Alberto Medeiros. Rio de Janeiro: Jorge Zahar Ed., 2005.

BENHABIB, Seyla. Las reivindicaciones de la cultura: igualdad y diversidad en la era global- Tradución de Alejandra Vassallo. La Ed. Buenos Aires: Katz, 2006.

CESNIK, Fábio de Sá; BELTRAME, Priscila Akemi. Globalização da cultura. Barueri, SP: Manole, 2005. 
DÜSING, Klaus. Modelos de autoconsciência. Críticas modernas e propostas sistemáticas referentes à subjetividade concreta. Traduzido por Ilson Kayser. São Leopoldo: UNISINOS, 2006.

ESCOBAR, Arturo. O lugar da natureza e a natureza do lugar: globalização ou pósdesenvolvimento. In: LANDER, Edgardo (org). A colonialidade do saber e ciências sociais: perspectivas latino-americanas. Buenos Aires: CLACSO, 2005.

FONTES, Nancy Rita Vieira. Identidade e alteridade em João Ubaldo Ribeiro: um brasileiro em Berlim. Texto s.d.

GADAMER, Hans-Georg. Verdad y método I. Fundamentos de una hermenéutica filosófica. 6 ed. Salamanca: Ed. Sígueme, 1996. Sígueme, 1994. Verdad y método II. $2^{\mathrm{a}}$ ed. Salamanca: Ed.

GIDDENS, Anthony. Modernidade e identidade. Traduzido por Plínio Dentzien. Rio de Janeiro: Jorge Zahar Editores, 2002.

HALL, Stuart. A identidade cultural na pós-modernidade. Rio de Janeiro: DP\&A, 1999.

LACERDA, Rosane Freire."Volveré, y SeréMillones": Contribuições Descoloniais dos Movimentos Indígenas Latino Americanos para a Superação do Mito do Estado-Nação. I Rosane Freire Lacerda. Brasília - DF, 2014.

OLIVEIRA. Roberto Cardoso. Caminhos da identidade: ensaios sobre etnicidade e multiculturalismo. São Paulo: Editora Unesp; Brasília: Paralelo, 2006.

OLIVEIRA, Manfredo Araújo de. Antropologia filosófica contemporânea: subjetividade e inversão teórica. São Paulo: Paulus, 2012.

MIGNOLO, Walter. "Desobediência Epistêmica: a opção descolonial e o significado de identidade empolítica". Cadernos de Letras da UFF - Dossiê: Literatura, língua e identidade, $n^{\circ} 34$, p. 287-324, 2008.

MIGNOLO, Walter.El pensamiento decolonial: desprendimiento y apertura. Um manifiesto. In: CASTRO-GÓMEZ, Santiago; GROSFOGUEL; Ramón (Orgs.). El giro decolonial. Reflexiones para una diversidad epistémica más allá del capitalismo global. Bogotá: Siglo del Hombre-Iesco-Pensar, 2007, p. 25-45.

PAREYSON, Luigi. Verdade e interpretação. Traduzido por Maria Helena Nery Garcez e Sandra Neves Abdo. São Paulo: Martins Fontes, 2005.

PAVIANI, Jayme. Cultura, humanismo e globalização. Caxias do Sul, RS: Educs, 2004.

RICOEUR, Paul. O justo 1: a justiça como regra moral e como instituição. Traduzido por Ivone C. Benedetti. São Paulo: Martins Fontes, 2008.

RICOEUR, Paul. O si-mesmo como outro. Traduzido por Ivone C. Benedetti. São Paulo: Martins Fontes, 2014.

RICOEUR, Paul. A ideologia e a utopia. Traduzido por Sílvio Rosa Filho e Thiago Martins. Belo Horizonte: Autêntica, 2015. 
Simpatia e rispetto. Fenomenologia ed ética dellaseconda persona, in LEVINAS, E.,

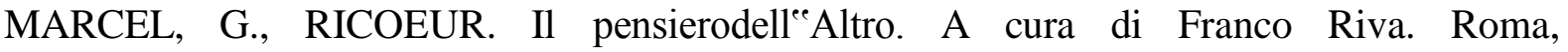
EdizioniLavoro, 1955.

ROUANET, Sergio Paulo. As razões do Iluminismo. São Paulo: Companhia das Letras, 2005.

SALLES, Walter. Paul Ricouer e a hermenêutica de si no espelho das palavras. Utopia y PraxisLatinoamericana. Maracaibo , v. 14, n. 47, p. 41-58, dic. 2009.

Disponibleen<http://www.scielo.org.ve/scielo.php?script=sci_arttext\&pid=S1315$52162009000400004 \& \operatorname{lng}=$ es\&nrm=iso>. Accedidoen 17 enero 2016.

SANTAMARIA, RosembertAriza. Descolonização juridical nos Andes.In.WOLKMER, Antonio Carlos; LIXA, Ivone Fernandes M. (Orgs.) Constitucionalismo, descolonización y pluralismo jurídico en América Latina. Aguascalientes: CENEJUS / Florianópolis: UFSCNEPE, 2015.

SANTOS, Boaventura de Sousa. A gramática do tempo: para uma nova cultura política. 2 ed. São Paulo: Cortez, 2008.

SIDEKUN, Antonio.Identidade e Alteridade. In. TREVISAN, Amarildo; TOMAZETTI, Elizete (Orgs.). Cultura, Alteridade e confluências. Ijui, 2006.Disponível em: www.ufsm.br/gpforma/universenaf1.pdf. Data de acesso: 10 de janeiro 2016.

STEIN, Ernildo. Antropologia filosófica: questões epistemológicas. Ijuí: Editora Unijuí, 2010.

TAYLOR, Charles. As fontes do self. A construção da identidade moderna. Traduzido por Adail Ubirajara Sobral e Dinah de Abreu Azevedo. São Paulo: Edições Loyola, 2011.

.Multiculturalismo. Lisboa: Instituto Piaget, 1998.

ZAOUAL, Hassan. Globalização e diversidade cultural. Tradução de Michel Thiollent. São Paulo: Cortez, 2003.

WALSH, Catherine. "Interculturalidad y Colonialidaddel Poder: unpensamiento y posicionamientootro desde la diferencia colonial". In: Santiago CASTRO-GÓMEZ e Ramón Grosfoguel (Eds.). El Giro Decolonial. Reflexiones para una diversidadepistémica más alládel capitalismo global. Bogotá: SigloDel Hombre Editores; Universidad Central, Instituto de EstudiosSocialesContemporáneos y Pontificia Universidad Javeriana, Instituto Pensar, 2007.

WALSH, Catherine.Interculturalidad, estado, sociedade: luchas (de)coloniales de nuestra época. Quito-Equador: Universidade Andina Simón Bolívar/EdicionesAbya-Yala, 2009.

WOLKMER, Antonio Carlos. Pluralismo jurídico, movimentos sociais e processos de luta desde América latina. In.WOLKMER, Antonio Carlos; LIXA, Ivone Fernandes M. (Orgs.) Constitucionalismo, descolonización y pluralismo jurídico en América Latina. Aguascalientes: CENEJUS / Florianópolis: UFSC-NEPE, 2015. 